\title{
Policies and practices that link Accountability to Affected Populations (AAP) and Protection from Sexual Exploitation (PSEA)
}

Laura Bolton

IDS

21 September 2021

\section{Question}

What evidence is available on the policies and practices that link Accountability to Affected Populations (AAP) and Protection from Sexual Exploitation and Abuse (PSEA)? Where possible please include lessons learned from implementation showing best and poor practices, and implementation modalities (integration, coordination, etc).

\section{Contents}

1. Summary

2. Inter-Agency Standing Committee (IASC)

3. Core Humanitarian Standard (CHS) on Quality and Accountability

4. Inclusion of PSEA in agency AAP documents

5. Communication and community engagement

6. References

The K4D helpdesk service provides brief summaries of current research, evidence, and lessons learned. Helpdesk reports are not rigorous or systematic reviews; they are intended to provide an introduction to the most important evidence related to a research question. They draw on a rapid deskbased review of published literature and consultation with subject specialists. 


\section{Summary}

Documents identified for this report show that largely protection from sexual exploitation (PSEA) is incorporated into accountability for affected population (AAP) policy and practice. In 2014 the Inter-Agency Standing Committee (IASC) merged two task forces on these into one. IASC look at linkages between AAP and PSEA processes highlighting that:

- risks of SEA should be understood and mitigated within AAP

- feedback and complaints processes can be used for both areas

- information for communities should be provided so that they know what behaviour to expect from aid workers in all areas

- affected people should feed into SEA survivor packages

The general consensus across organisations is that SEA constitutes the most serious breach of AAP.

The Core Humanitarian Standard (CHS) Alliance published a PSEA index mapping CHS verification indicators with PSEA requirements. Documented experience of using this and other policies and tools were not identified within the scope of this report. More is needed in the humanitarian community to report practical experience in linking AAP and PSEA

Agency documents on AAP include PSEA as core components. Text on AAP and PSEA references IASC information. Section 4 of this report looks at inclusion of PSEA in the UNICEF AAP handbook, UNHCR guidance, WHO guidance, and International Organisation of Migration policy.

PSEA is suggested to be included in messaging at the onset of emergencies. Communities should be engaged with understanding their rights and how to act if their rights have been breached. Training is required for agencies to provide confidential, trusted and safe referral. Having a PSEA focal point is recommended.

\section{Inter-Agency Standing Committee (IASC)}

The IASC definition of AAP is "An active commitment to use power responsibly by taking account of, giving account to, and being held to account by the people humanitarian organizations seek to assist"1.

In 2012 the IASC established two task forces, one on Accountability to Affected Populations (AAP) and one on Protection from Sexual Exploitation and Abuse (PSEA) by humanitarian workers. In 2014 these two task forces were combined as the IASC AAP/PSEA Task Team. ${ }^{2}$ The objectives of the Team are to foster accountability and protection at all levels of the humanitarian system; encourage institutionalisation of AAP and PSEA, and support operationalisation.

\footnotetext{
${ }^{1}$ https://interagencystandingcommittee.org/system/files/iasc_aap_psea_2_pager_for_hc.pdf

2 https://interagencystandingcommittee.org/iasc-task-team-on-accountability-to-affected-populations-andprotection-from-sexual-exploitation-and-abuse-aap-psea
} 
They produced a diagram describing AAP and PSEA processes and results of linkages (figure 1). ${ }^{3}$

Figure 1: Linkages between Accountability to Affected Persons and Prevention of Sexual Exploitation and Abuse

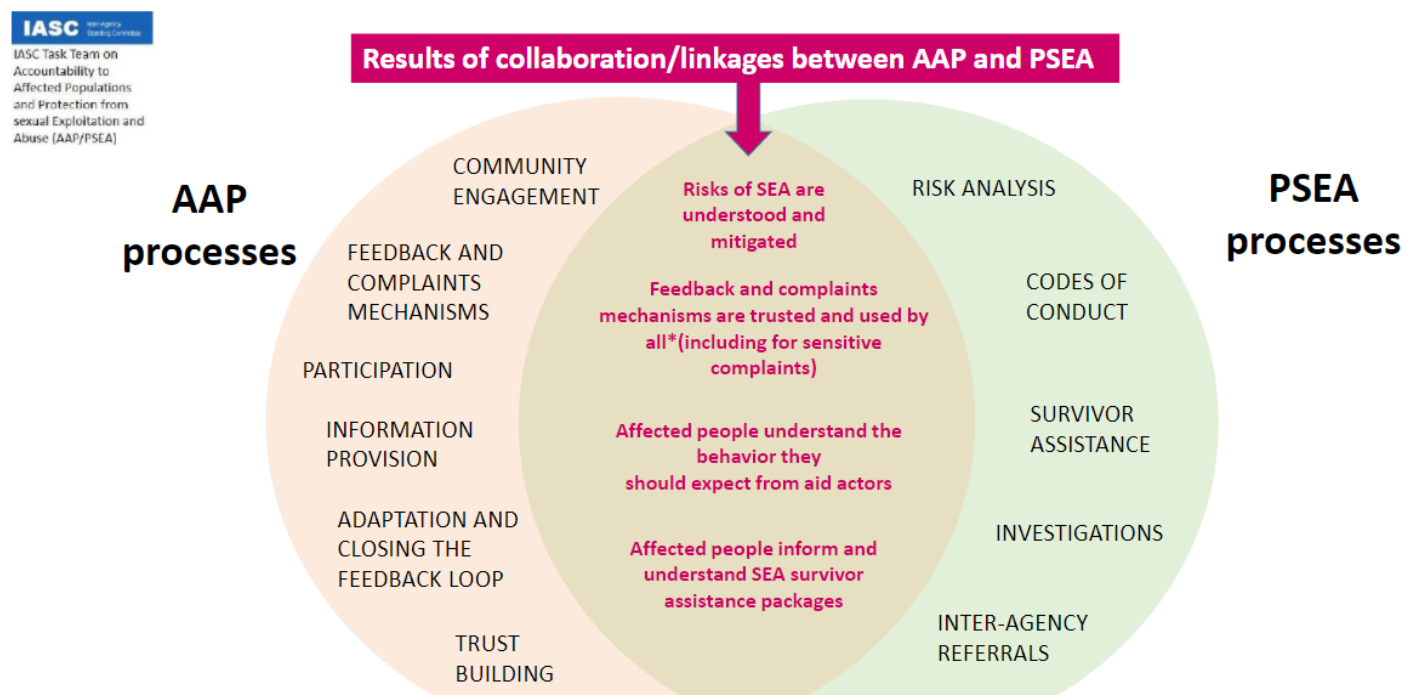

Source: IOM (2019) reproduced under CC BY 4.0

Linkages between AAP and PSEA outlined in figure 1 are:

- That risks of SEA are understood and mitigated within AAP

- Feedback and complaints processes can be used for both AAP and PSEA

- Information for communities on what behaviour they should expect overlaps

- Affected people can feed into SEA survivor assistance packages.

The text that accompanies the diagram provides a simple explanation for the linkage between AAP and PSEA: "Sexual Exploitation and Abuse (SEA) constitutes the most egregious breach of Accountability to Affected Populations (AAP) and measures must be in place at both the community level (AAP)and organization level (PSEA) to prevent it, protect affected populations from it and contribute to safer programming". PSEA is included as a part of AAP rather than something separate. AAP on the other hand, includes PSEA, among other areas.

\footnotetext{
${ }^{3}$ https://interagencystandingcommittee.org/iasc-task-team-accountability-affected-populations-and-protectionsexual-exploitation-and-abuse-2
} 
Checklists and guidance 4 for PSEA fall under the AAP umbrella but do not mention AAP specifically. Information on PSEA during the COVID ${ }^{5}$ response in humanitarian emergencies did not talk about AAP explicitly, rather it might be considered that PSEA constitutes AAP implicitly.

Published minutes of IASC AAP PSEA Task Team Meeting ${ }^{6}$ outline priority outcomes for PSEA, propose a system-wide structure at country level, and provides guidance on tracking progress for PSEA implementation. It describes activities on developing tools, compiling and sharing lessons, conducting a mapping of PSEA networks, and increasing capacity of PSEA coordinators. It comments on the issue of language issues between needing to report SEA and those gathering reports.

The IASC have a best practice guide on complaints mechanisms specifically for SEA. ${ }^{7}$

\section{Core Humanitarian Standard (CHS) on Quality and Accountability}

PSEA is essential to the CHS. ${ }^{8}$ The CHS Alliance published an updated PSEA index so that organisations verifying their performance can determine whether they have the policies and practices in place to protect people in vulnerable situations (CHS Alliance, 2020). Safeguarding requirements are described for relevant indicators of the $\mathrm{CHS}$ verification framework. The index includes PSEA requirements, PSEA guiding questions, and recommended evidence for specific CHS indicators.

Reported experience on working with this PSEA index was not identified within the scope of this report.

\footnotetext{
${ }^{4}$ E.g. UN Implementing Partner PSEA Capacity Assessment https://interagencystandingcommittee.org/iasc-taskteam-accountability-affected-populations-and-protection-sexual-exploitation-and-abuse/un-implementing-partnerpsea-capacity-assessment and Checklist to Protect from Sexual Exploitation and Abuse during COVID-19 https://interagencystandingcommittee.org/iasc-task-team-accountability-affected-populations-and-protectionsexual-exploitation-and-abuse/checklist-protect-sexual-exploitation-and-abuse-during-covid-19

${ }^{5}$ PSEA during COVID-19 Response: Field Examples of Adaption of IASC guidance https://interagencystandingcommittee.org/iasc-task-team-accountability-affected-populations-and-protectionsexual-exploitation-and-abuse/psea-during-covid-19-response-field-examples-adaption-iasc-guidance

${ }^{6}$ https://interagencystandingcommittee.org/system/files/aap_psea_tt_meeting_7_feb_2019.pptx IASC AAP PSEA Task Team Meeting 7 June 2018

${ }^{7}$ https://reliefweb.int/sites/reliefweb.int/files/resources/best_practice_guide_on_establishing_interagency_cbcms.pdf

${ }^{8}$ https://aap-inclusion-psea.alnap.org/help-library/chs-pseah-index
} 


\section{Inclusion of PSEA in agency AAP documents}

Agency documents refer to IASC standards heavily.

\section{UNICEF}

\section{UNICEF 2020 Accountability to Affected Populations Handbook ${ }^{9}$}

PSEA is included in the implementation section of this AAP handbook (UNICEF, 2020). It is mentioned in the list of considerations for a situation analysis under feedback and complaints mechanism. PSEA is suggested to be included in messaging at the onset of an emergency. The handbook recommends establishing a robust, secure referral system and protocol for complaints related to SEA. The system should include an up-to-date list of local service providers for survivors of SEA.

An example of programme activity states that staff partners in Haiti, Action Contre la Faim, have been trained in handling PSEA and responding to complaints. UNICEF Cameroon include indicators on trust in SEA report mechanisms.

The document includes a chapter on PSEA including commitment and standards of conduct. The handbook notes that linking AAP and PSEA are particularly "the links between AAP and PSEA are particularly relevant when looking at information-sharing and reporting through complaints and feedback mechanisms" (p82). It describes core principals of effective reporting for SEA under the headings: safe, confidential, transparent, and accessible.

A case study reports experience in Mozambique following a cyclone when a PSEA national network was established by the Humanitarian Country Team (HCT). The coordinator sent a clear message to the network that PSEA was a priority. The network rolled out an action plan containing indicators for tracking progress. Accommodation centres were sent information to display on SEA reporting and 2 million text messages were sent on both the prohibition of SEA and the right to receive humanitarian aid for free.

Guidance on supporting the interconnectedness of AAP and PSEA with partnerships includes:

- Having PSEA focal points to provide technical support to embed PSEA into all programmes.

- Ensuring all partners are part of prevention efforts for joined up accountability.

- Making sure AAP and PSEA are standing agenda items in HCT and inter-agency coordination meetings.

- Building SEA reporting mechanisms with affected populations.

- Training staff who handle feedback and complaints in PSEA procedures.

- Sharing PSEA information at every available opportunity.

\footnotetext{
${ }^{9}$ https://reliefweb.int/sites/reliefweb.int/files/resources/UNICEF_AAP_Handbook_EN.pdf
} 


\section{Summary Guidelines to Integrating Accountability to Affected People (AAP) into Country Office Planning Cycles ${ }^{10}$}

AAP in UNICEF is built around 7 principles of accountability. One of these pillars is PSEA (UNICEF, 2020b). PSEA is mentioned throughout the report in regards to planning, situation analysis, cross-cutting delivery, and mechanism mapping.

\section{UNHCR}

\section{Operational guidance on accountability to affected people (AAP) ${ }^{11}$}

These guidelines include PSEA as one of the underlying principles of UNHCR's approach (UNHCR, 2020). "Sexual exploitation and abuse is regarded as the most egregious breach of accountability by the humanitarian community" (p8). Staff are required to report incidents of SEA. The guidelines state that standard operating procedures for SEA complaints will be specific but should be an integral part of existing feedback mechanisms.

Linkages between AAP and PSEA are described based on the IASC diagram in figure 1. The guidance states "AAP's link with PSEA is primarily to do with setting up confidential feedback systems, consulting with communities on their preferences for these mechanisms, and informing communities on how to access them" (p10). It says that mechanisms must allow people to make SEA complaints in a safe and confidential environment. And that this should be made possible if an AAP approach has been taken to establishing and running a feedback mechanism supporting people to trust in the system. Trust is critical. PSEA incorporation into AAP should take a community-based approach, include a commitment to confidentiality, and ensure safety of the complainant and of staff. PSEA focal point contact person within the feedback and response loop.

The guidance directs to specific reports on UNHCR intranet for receiving complaints and reporting on sexual abuse.

\footnotetext{
${ }^{10}$ https://www.unicef.org/esa/media/7101/file/UNICEF-ESA-Intergrating-AAP-2020.pdf.pdf

${ }^{11}$ https://www.unhcr.org/handbooks/aap/documents/UNHCR-AAP_Operational_Guidance.pdf
} 


\section{WHO}

\section{Health Cluster Operational Guidance on Accountability to Affected Populations (AAP) ${ }^{12}$}

This document includes a section on PSEA (Health Cluster, 2017). It quotes the WHO Code of Ethics and Professional Conduct ${ }^{13}$ on the importance of staff vigilance in refraining from actions that may suggest or imply that a sexual act is a condition for service. It also references the WHO Policy on the Prevention of Harassment ${ }^{14}$ which provides a mechanism to prevent SEA from staff members or collaborators.

One of the coordination actions to support people-centred approaches describes consulting with specialised agencies to ensure AAP, gender, protection and diversity issues are appropriately addressed. Another action is to increase awareness of Health Cluster partners on AAP, gender, protection and diversity to have zero tolerance for SEA.

\section{International Organisation of Migration (IOM)}

\section{Accountability to Affected Populations framework ${ }^{15}$}

This framework enforces the IOM provision zero tolerance against SEA with policies and procedures (IOM, 2020). Provisions for standards of conduct state that all staff must protect against and prevent SEA.

\section{Frequently Asked Questions on inter-agency PSEA. IOM's lessons learned from PSEA implementation in-country ${ }^{16}$}

This document discusses inter-agency community-based complaint mechanisms (CBMC) $)^{17}$ which aim to solve the issue that existing AAP mechanisms often struggle to deal with SEA

\footnotetext{
12 https://www.who.int/docs/default-source/documents/publications/operational-guidance-on-accountability-toaffected-populations.pdf?sfvrsn=ec7fb6c8_1

${ }^{13}$ https://www.who.int/about/ethics/code_of_ethics_full_version.pdf

${ }^{14}$ https://uploads-

ssl.webflow.com/5d6dfc1714166128aae8ffe7/5d762ffa34bd36e080e999e2_policyofthepreventionofharassmentat who-sept2010.pdf

15 https://publications.iom.int/system/files/pdf/iom-aap-framework.pdf

${ }^{16}$ https://interagencystandingcommittee.org/system/files/2020-04/IOM\%27s\%20FAQs\%20on\%20InterAgency\%20PSEA\%20\%282019\%29_0.pdf

17 a system blending both formal and informal community structures, built on engagement with the community where individuals are able and encouraged to safely report grievances and those reports are referred to the appropriate entities for follow-up
} 
complaints. "As the inter-agency $\mathrm{CBCM}$ links existing mechanisms directly to the person/unit responsible for SEA in an organization, these (AAP) mechanisms will be strengthened to be able to handle sensitive complaints" (IOM, 2019, p8).

This document takes the approach of incorporating AAP into PSEA, rather than the other way round as has been in other documents. It notes that past SEA prevention and response programmes have been inward focussed such as internal policymaking, staff trainings, and internal investigations. An outward focused programme would be more accountable to the affected population it serves. This outward focus takes on AAP strategies of community engagement, information sharing, and community feedback mechanisms for PSEA to be localised and needs based.

\section{Inter-agency Coordination Platform for Refugees and Migrants from Venezuela (R4V)}

\section{Guide on the integration of AAP and PSEA in the activities for the RMRP $2022^{18}$}

This guide describes the links between AAP and PSEA, chiefly that SEA constitutes one of the most serious breaches of accountability. And that issues of lack of accountability and of SEA come from asymmetries of power. The guide states the importance of complaints and feedback mechanisms able to deal with SEA allegations. "National and sub-regional Platforms must ensure AAP and PSEA strategies, networks/groups and reporting mechanisms are strongly linked and build upon their respective added value." (p3).

\section{Communication and community engagement}

The CDAC (Communicating with Disaster Affected Communities) Network produced a guide on collective communication and community engagement in humanitarian action (CDAC Network, 2019) which was recommended by an expert for this report. The report includes the IASC diagram on AAP and PSEA overlap (figure 1).

It notes that codes of conduct for PSEA, training, and complaints processes may not be enough. Community members may not feel there is an appropriate way to complain, may not understand their rights, and perpetration by intermediaries or community leaders may go unnoticed.

The guide recommends engaging with communities on their rights, providing clear information on how to act when rights are breached, clear referral pathways, and a process for identifying trends in complaints, and training for staff and all stakeholders.

18 https://www.r4v.info/en/document/guide-integration-aap-and-psea-activities-rmrp-2022 


\section{References}

CDAC Network (2019). Collective Communication and Community Engagement in humanitarian action. How to Guide for leaders and responders.

http://www.cdacnetwork.org/contentAsset/raw-data/cca52f57-4f06-4237-9c18-

37b9e8e21a18/attachedFile2

CHS Alliance (2020). Revised CHS PSEAH index (October 2020). https://aap-inclusionpsea.alnap.org/help-library/chs-pseah-index

Health Cluster (2017). Operational Guidance on Accountability to Affected Populations (AAP). WHO and USAID. https://www.who.int/docs/default-

source/documents/publications/operational-guidance-on-accountability-to-affectedpopulations.pdf?sfvrsn=ec7fb6c8_1

IOM (2020). Accountability to Affected Populations framework.

https://publications.iom.int/system/files/pdf/iom-aap-framework.pdf

IOM (2019). Frequently Asked Questions on inter-agency PSEA. IOM's lessons learned from PSEA implementation in-country. https://interagencystandingcommittee.org/system/files/202004/IOM\%27s\%20FAQs\%20on\%20Inter-Agency\%20PSEA\%20\%282019\%29_0.pdf

UNICEF (2020a). Accountability to affected populations. A handbook for UNICEF and partners. https://reliefweb.int/sites/reliefweb.int/files/resources/UNICEF_AAP_Handbook_EN.pdf

UNICEF (2020b). Summary Guidelines to Integrating Accountability to Affected People (AAP) into Country Office Planning Cycles. UNICEF Eastern and Southern Africa Regional Office. https://www.unicef.org/esa/media/7101/file/UNICEF-ESA-Intergrating-AAP2020.pdf.pdf

UNHCR (2020). Operational guidance on accountability to affected people (AAP). https://www.unhcr.org/handbooks/aap/documents/UNHCRAAP_Operational_Guidance.pdf

\section{Acknowledgements}

We thank the following experts who voluntarily provided suggestions for relevant literature or other advice to the author to support the preparation of this report. The content of the report does not necessarily reflect the opinions of any of the experts consulted.

- Mariska De Keersmaecker, IOM

- Katherine Harris, Accountability and Inclusion Helpdesk 


\section{Suggested citation}

Bolton, L. (2021). Policies and practices that link Accountability to Affected Populations (AAP) and Protection from Sexual Exploitation (PSEA). K4D Helpdesk Report 1028. Brighton, UK: Institute of Development Studies. DOI: 10.19088/K4D.2021.138

\section{About this report}

This report is based on six days of desk-based research. The K4D research helpdesk provides rapid syntheses of a selection of recent relevant literature and international expert thinking in response to specific questions relating to international development. For any enquiries, contact helpdesk@k4d.info.

K4D services are provided by a consortium of leading organisations working in international development, led by the Institute of Development Studies (IDS), with Education Development Trust, Itad, University of Leeds Nuffield Centre for International Health and Development, Liverpool School of Tropical Medicine (LSTM), University of Birmingham International Development Department (IDD) and the University of Manchester Humanitarian and Conflict Response Institute (HCRI).

This report was prepared for the UK Government's Foreign, Commonwealth and Development Office (FCDO) and its partners in support of pro-poor programmes. Except where otherwise stated, it is licensed for non-commercial purposes under the terms of the Open Government License v3.0. K4D cannot be held responsible for errors, omissions or any consequences arising from the use of information contained in this report. Any views and opinions expressed do not necessarily reflect those of FCDO, K4D or any other contributing organisation.



(C) Crown copyright 2021. 